\title{
AS IMPORTAÇÕES PARALELAS \\ NAS RELAÇÕES REGIONAIS: \\ A EXAUSTÃO DOS DIREITOS DE \\ PROPRIEDADE INTELECTUAL \\ NO DEBATE SOBRE A ALCA
}

Valesca Raizer Borges Moschen*

SUMARIO: 1. Introdução. 2. Análise subjetiva do consentimento nas itmportaçôes paralelas. 2.1. Importaçōes paralelas entre empresas vinculadas. 2.2. Importaçôes Paralelas entre licenciados. 3. Análise objetiva do consentimento: consentimento em função da natureza do produto. 4. Limites geográficos e a aplicaça do princípio de exaustão de direitos. 4.1. Modelos regionais e os limites internacionais da exaustão. 4.2. A regulamentação multilateral sobre a exaustão internacional dos direitos de propriedade intelectual: linhas de um debate subjetivo. 5. Conclusão. 6. Bibliografia.

SUMMARY: 1.Introduction. 2. Subjective analisys of the assentment in parallels importation. 2.1. Parallel Importation bars between entailed companies. 2.2. Permitted Importantion between licenced companies. 3. Objective analysis of assentment: assentment in function of the products' nature. 4. Geographic limits and the application of the principle of exhaustion of rights. 4.1. Regronal models and the international limits of the exhaustion. 4.2. The multilateral regulation on the international exhaustion of intelectual property: lines of a subjective debate. 5. Conclusion. 6. Bibliography.

SUMARIO: 1. Introducción. 2. Análisis subjetiva del asentimiento en las importaciones paralelas. 2.1. Barrases paralelas de la importación entre las compañias exigidas. 2.2. Barrases paralelas de las importaciones de Licenciados. 3. Análisis entre el objetivo del asentimiento: asentimiento en la función de la naturaleza del producto. 4. Los límites geográficos y el uso hacen el principio del agotamiento de las derechas. 4.1. Modelos regionales y los límites internacionales del agotamiento. 4.2. La regulación multilateral sobre el agotamiento internacional de los derechos de la propiedad intelectual: Las lineas de una han discutido subjetivo. 5. Conclusión. 6. Bibliografia.

\footnotetext{
"Doutonit en Direito e Professora da Faculdade de Direito da Universidade Federal do Espirito Santo.
} 
RESUMO: Tradicionalmente, na concepça do direito de propriedade intelectual - de certa forma, uma espécie do direito de propriedade - (desentvolvido, através da consolidação do capitalismo industrial e do próprio Estado moderno) duas foram às tensóes inerentes a sua regulamentação: de um lado, a necessidade de se legitimar, via intervença estatal, o desenvolvimento da Empresa e, com ela, a propriedade não apenas dos bens corpóreos, mas, também, de seus produtos simbólicos e, especialmente, de seu domínio da ciência e tecnologia; e, de outro, o fomento do livre mercado, que tende a promover, em algumas circunstâncias, a flexibilização do monopólio de exploração, concedido pelo Estado, ao titulat de um direito de propriedade intelectual. No tema das Importaçóes Patalelas, ou seja, importações realizadas por pessoas fisicas ou jurídicas, fora dos circuitos de distriburição exclusiva, em um território, de produtos legitimamente comercializados em outro território, esse conflito ganha especial relevância. Confrontam-se: - o interesse do titular de um direito de propriedade industrial, em controlar a distribuição do seu produto no mercado nacional, regional efou internacional, através do estabelecimento de redes próprias de distribuiça ou de revenda consentida de seu produto; - os interesses de consumidores, terceiros revendedores, e, de certa forma, do próprio processo de integração e, por que não, de mundialização, que proclamam a diminuição das barreiras para a importação de mercadorias. Este artigo tem como objetivo trazer para dentro do debate sobre propriedade intelectual da Area de Livre Comércio das Américas - ALCA - o tema da exaustão dos direitos de propriedade intelectual e as suas perspectivas frente ao novo desafio da integração regional. Nesse contexto, o presente trabalho buscará analisar os limites entre os extremos da exploração monopólica dos direitos de propriedade intelectual versus a livre circulaça de bens num mercado regional.

ABSTRACT: Traditionally, intelectual property rights are - of certain form, a species of the property right - (developed, through the consolidation of the industrial capitalism and the proper modern State) the two inherent tensions of its regulation are: the necessity of if legitimizing, through state intervention, the development of a Company and, consequently, the property not only of the corporal objects, but, also, of its symbolic products and,

1 DEL NERO, Patricia Aurélia, (in Propriedade Intelectual: a tutela juridica da biotecnologia. Saro Paulo: Revista dos Tribunais, 1998 , pag. 31), afima que o desenvolvinento do dircito de propriedade intelectual é fruto da forma moderna da propriedade "direito exclusivo, que em caráter permanente, se ten sobre a coisa que pertence a um titular" que adequada o mundo burguềs e à economia capitalista, consagrasse en assegurar o domínio, "não apenas sobre as coisas en si, mas, sobretudo, sobre todas as possibilidades criação do valor econónico", entre elas a própria capacidade intelectual e criativa do homem, que no capitalismo industrial, tona-se mercadoria. 
especially, of its domain of science and technology, and on the other hand, the promotion of free marker, that tends to promote, in some circumstances, flexibilization of monopoly of explotation, granted for State, to the bearer of a right of intelectual property. About Parallel Importation, or either, importations carried through for physical or legal people, out of the circuits of exclusive distribution, in a territory, of products legitimately commercialized in another territory, this conflict gains special relevance. There are collated: - the interest of bearer of an industrial property law, in controlling the distribution of its product in national, regional and/or international market, through establishment of proper nets of distribution or assented resale of its product; - consumers interests, peddlers, and, of a certain form, the proces of integration and, why not, mundialization, that proclaim the reduction of the barriers for importation of merchandises. This article has as objective to bring up the debate on intelectual property in the Area of Free Commerce of Americas ALCA - the subject of exhaustion of the rights of intelectual property and its perspectives face new challenges of regional integration. In this context, this work will analyze limits between extremities of the monopolical explotation of intelectual property rights versus free circulation of goods in a regional market.

RESUMEN: Tradicionalmente, en el concepto de lo derecho de la propiedad intelectual - de cierta forma, wna especie de lo derecho de propiedad (desarrollado, con la consolidación del capitalismo industrial y del estado moderno) dos habian sido las tensiones inherentes a su regulación: de un lado, la necesidad de legitimizarse, por la intervención del estado, el desarrollo de la compafía y, con ella, la propiedad no solamente de los objetos corpóreos, pero, también, de sus productos simbólicose, especialmente, de su dominio de la ciencia y de la tecnologia; e, de otra, la promoción del mercado libre, que tiende para promover, en algunas circunstancias, el flexibilización del monopolio de la exploración, concedido para el estado, al portador de una derecha del copyright. En el tema de las barrases paralelas de las importaciones, $o$, de las importaciones llevadas a través para la persona fisica o legal, fuera de los citcuitos de la distribación exclusiva, en un territorio, de los productos comercializados legítimo en otro territorio, esta importancia especial de los aumentos del conflicto. Se compaginan: - el interés del portador de una ley de la propiedad industrial, en controlat la distribución de su producto en el mercado nacional, regional e internacional, através del establecimiento de redes apropiadas de la distribución o de la reventa consentida de su producto; - los intereses de consumidores, de los terceros vendedores ambulantes, $y$, de cierta forma, del proceso apropiado de la 
integración y, porqué no, de mundialización, de que proclame la reducción de las barreras para la importación de comercializan. Este artículo tiene como objetivo a traer para dentro del discusión sobre el derecho de la propiedad intelectual en la Área del Libre Comercio de Américas ALCA - el tema del agotamiento de los derechos de la propiedad intelectual y sus perspectivas afrontan al nuevo desafio de la integración regional. En este contexto, el actual trabajo buscará para analizar los límites entre las extremidades de la exploración monopolica de los derechos de la propiedad intelectual contra la circulación libre de mercancías en un mercado regional.

PALAVRAS-CHAVE: Importações Paralelas. Área de Livre Comércio das Américas. Exaustão dos direitos de propriedade intelectual. Propriedade Industrial.

KEY-WORDS: Parallel Importation. Area of Free Commerce of Americas. Exhaustion of the rights of Intelectual Property. Industrial Property.

PALABRASLLAVE: Barrases paralelas de la importación. Área del Libre Comercio de Américas. Agotamiento de los derechos de la propiedad intelectual. Propiedad Industrial.

\section{Introdução}

O princípio da exaustão do direito de propriedade intelectual - originário do desenvolvimento jurisprudencial alemão, no início do século ${ }^{2}$ vem sendo entendido, como uma limitação ao direito de exploração exclusiva da propriedade intelectual, a partir da seguinte acepção:

"o direito de exclusividade não confere ao titular o poder de controlar a revenda do produto protegido, uma vez que este tenha sido colocado no mercado por ele ou por seus licenciados"

A legitimidade e regulamentação da aplicação do princípio de exaustão condicionam-se, especialmente, a duas questóes primordiais ${ }^{4}$ :

a) As hipóteses de incidência da exaustão, ou seja, seus requisitos; e

b) a sua amplitude geográfica;

\footnotetext{
${ }^{2}$ Sobre a origem do princípio de exaustão vid BEIER, Friedrich-Karl, in "Propriedad Industrial y libre circulación de mercancías en el mercado interior y en el comercio com terceros Estados", Revista General de Derecho, $\mathrm{n}^{2}$ 549, Junho, Valencia, 1990, pag.4.528.

"ALEXANDER, Willy, "Exhaustion of Trade Mark Rights in the European Economic Area", European Law Review, vol.24, fevereiro, 1999, pp. 56-67.

"FEKETE, Elizabeth K., "Importações Paralelas: A implementação do princípio de exaustão de direitos no Mercosul, diante do contexto de globalização", Anais do XXVI Seminário Nacional de Propriedade Intelectual,1997, pp. 76-102. Publicado, também, na Revista do Direito Mercantil, Industrial, Econômico e Financeiro, vol 113, janeiro-narço, 1999, pp.154-187.
} 
Na primeira questão, o principal requisito da incidência da exaustão dos direitos ora trabalhados, é a qualificação do consentimento do titular de um direito de propriedade industrial às importações e comercializações de seu produto original. Problemática submetida ao jus prohibendi do titular do direito.

Dessa forma, é o consentimento a peça angular na delimitação das hipóteses de aplicação do princípio de exaustão de direitos de propriedade industrial nas importações paralelas.

$\mathrm{Na}$ segunda questão, a incidência da exaustão desses direitos relaciona-se com o limite da dimensão territorial, se nacional, regional ou internacional, imposto por determinados ordenamentos juridicos, no afã de flexibilizar o monopólio de sua exploração, promovendo a livre circulação de mercadorias em um determinado território.

O presente artigo está desenvolvido em duas partes, a saber: na primeira, na qual será analisada a qualificação do consentimento, o tema se bifurca na análise subjetiva e objetiva da questão. Na segunda, onde serão estudados os limites geográficos como ponto turbulência na limitação dos direitos de propriedade industrial, a partir de uma análise da exaustão internacional dos mesmos.

Diversos são os caminhos para a análise da qualificação do consentimento para a incidência da exaustão dos direitos de propriedade intelectual. Desde uma vertente subjetiva, o debate sobre o consentimento vincula-se às relações interempresariais que envolvem as importações paralelas. Desde uma vertente objetiva, o consentimento estende-se à própria natureza do produto em circulação, objeto de uma importação paralela. Ambos caminhos serão a seguir percorridos.

\section{Análise subjetiva do consentimento nas importaçōes paralelas}

O consentimento, ato de consentir ${ }^{5}$, estar de acordo com, anuir, autorizar, pode ser realizado de forma expressa ou tácita. $O$ consentimento expresso é aquele resultante da "manifestação volitiva (escrita ou verbal) inequívoca, concordante com a prática de determinado ato " que, a princípio, não apresenta maiores dificuldades na limitação de sua abrangência.

As dificuldades que encontram os tribunais e doutrinadores ao buscarem

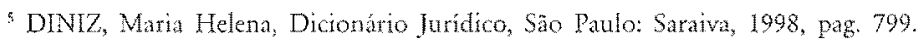

"FEKETE, Elisabeth Kaszmar, op.cit., pag. 84.
} 
soluçōes jurídicas para as importações paralelas residem, especialmente, na qualificação do consentimento tácito?.

Nessa classe de consentimento dois elementos são incorporados na sua definição, o elemento do controle, no qual a análise da existência e extensão do consentimento será fruto dos liames internos, societários ou contratuais, existentes entre a empresa exportadora e a importadora, e o elemento da extensão das cláusulas de territorialidade nos contratos de licença de exploração de direitos de propriedade intelectual, de licenças de distribuição e/ou fabricação de produtos.

Dentro dessa perspectiva, alguns critérios subjetivos identificadores do consentimento, e consequentemente, responsáveis pela legitimação das importações paralelas e, com elas, do princípio de exaustão, têm sido desenvolvidos, na busca de uma uniformidade no tratamento da matéria. Dentre os quais podemos citar os seguintes:

a) A exportação (venda) no mercado estrangeiro é realizada por sociedade controlada ou do mesmo grupo da sociedade titular do direito de propriedade no local de importação;

b) Quando a venda no mercado estrangeiro é realizada por licenciado do titular do direito de propriedade.

\subsection{Importações paralelas entre empresas vinculadas}

Um dos grandes desafios do direito mercantil moderno reside na identificação e classificação dos atos de concentração empresarial. A caracterização desse fenômeno traz embutida a célebre frase de Túlio Ascarelli ${ }^{9}$ "a desgraça da ciência jurídica está nas suas incertezas terminológicas".

Na busca da diminuição da ambigüidade do tema, a doutrina brasileira, através de Waldírio Bulgarelli ${ }^{10}$, afirma que a classificação e natureza de tais relaçốes estarão vinculadas ao maior ou menor grau de complexidade da própria relação interempresarial.

Dentro da visão das relações interempresárias, o célebre professor brasileiro Fábio Konder Comparato", ao trabalhar os grupos de sociedades,

\footnotetext{
Ou presumido, que é aquele em qué "não havendo a manifestaça expressa da vontade, a agente pratica atos revelados de sua intençáo de consentir na tealização do negócio juridico. É portanto, o consentimento decorrente da evidência de atos que demonstram a vontade de anuir à prática do negócio ou de aprová-lo".DINIZ, Maria Helena, op.cit., pag.800.

* Nesta perspectiva as interpretaçoes se diferenciam em função do espaço geográfico do limite da exaustão, se nacional, regional ou internacional.

"ASCARELLI, Túlio, Enciclopédia Juridica Soibelman, Rio de Janeiro:Saraiva, 1998.

"BULGARELLI, Waldirio, Concentração de empresas e Direito Anti-Trust, Säo Paulo:Atlas, 1996, pag. 56. "COMPARATO, Fábio K,O Poder de Controle na Sociedade Anônima,3.ed.,São Paulo:RT,1983,pp. 23 e ss.
} 
ensina que se pode classificar a concentração empresarial em função de uma maior ou menor relevância dos elementos de "unidade de controle" e "unidade de direção".

No primeiro, existe uma relação de subordinação, especialmente, em função de uma relação de propriedades de participações societárias que permite a uma sociedade deter o comando e o poder de definir as principais deliberações de outra, controlada pela primeira ${ }^{12}$.

A unidade de direção, existente nos grupos de coordenação, afasta a subordinação empresária, mas, busca, mesmo sem pressupor direito de comandar, a harmonização das politicas empresariais ${ }^{13}$.

Ambos os casos são temas controversos para o direito de propriedade industrial. Em alguns ordenamentos, como o norte-americano, presume-se o consentimento para a alocação do produto em outro mercado quando a empresa exportadora é controlada, parcial ou totalmente, pela empresa titular do direito de propriedade do local de comercialização do produto importado ${ }^{14}$.

A Suprema Corte dos Estados Unidos da América, em 1988, através do litígio K-Mark Corp. V Cartier (486 US 281 1987), interpretando a seção 526 Tariff Act de $1930^{15}$, que próbe a importação de qualquer mercadoria de empresas estrangeira, quando a mesma utilize marca de titularidade de um cidadão, sociedade ou associação criada ou organizada nos Estados Unidos e que tenha, neste mercado, registrada patente ou marca oficial, criou exceçôes a tal proibição, legitimando, assim, para casos concretos onde estejam presentes relações de concentração empresarial, a realização das importações paralelas e a conseqüente exaustão do direito de propriedade intelectual, sejam realizadas através de grupos de subordinação ou de direção ${ }^{16}$.

\footnotetext{
12. No Brasil, o artigo 243, da Lei $6.404 / 76$, sobre scciedades anônimas, entende por sociedade controladora aquela que "diretamente ou através de outras controladas, é titular de diretos de sócio que lhe assegurem, de modo permanente, preponderincia nas deliberaçoes sociais e o poder de eleger a maioria dos administradores".

${ }^{13}$ COMPARATO, Fábio K., op.cit, pag. 25.

Hesta é a experiência demonstrada na decisäo K.Mart Corp. v. Cartier, 486 US 281 (1987) da Suprema Corte dos Estado Unidos, relatiya a licitude das importaçoes paralelas de produtos cuja marca pertencia a sociedades controladas, inteiramente ou em conjunto, pela titular do direito de propriedade industrial nacional. Vid ABBOT"T, Frederick M., "Fints report (Final) to the committee on international trade law of the international law association on the subject of Paralled Importation", Jourral of International Economic Law, 1998, pag, 611.

15 HARLANDER, Lisa, "Exhaustion of trademark rights beyond the European Union in light of Silhouette Intenational Shimmed V. Hartlauer Handelsgesellschaft. Toward stronger protection of trademark right eliminating the gray market", Georgia Journat of International and Comparative Law, vol 28, $\mathrm{n}^{2} 2,2000, \mathrm{pp} .285-286$.

"a Corte concluiu que a legislação norte-americana não impede a importaçăo paralela de produtos manufaturados, onde exista o controle conjunto entre as partes da importação, ou seja, no caso de subsidiárias das empresas americanas, de empresas controladas de forma conjunta por uma terceira empresa americana, e, ainda, quando as empresas possuírem uma unidade de direçăo no gue diga respeito ios seus planos de atuação no exterior. Vid HARLANDER, Lișa, op.cit. pag. 287. 
Na realidade, alegando a ausência de autonomia de decisão em função da subordinação ocasionada pelo controle ou da unidade de direção, entendeu-se que o ato de introdução do produto no mercado nacional foi realizado pelo próprio titular do direito de propriedade intelectual local ${ }^{17}$.

Nem sempre esta posição é recepcionada pelos tribunais nacionais ou regionais. Na experiência européia, tal como demonstra a decisão HAG II (Caso 10/89 SA CNL - Sucurs New York v. Hag GF AG, 1990), a interpretação, entretanto, foi contrária à posição acima mencionada. No caso europeu, o Tribunal de Justiça das Comunidades Européias, foi taxativo ao afirmar que nas relações de importações paralelas entre sociedades de uma mesmo grupo "não cabe falar de consentimento, na medida em que este só existe, com relação a um ato praticado por outrem, não quanto a um ato praticado por si mesmo 18 ". Assim mesmo, o consentimento existente em qualquer ato realizados entre sociedades controladas é diferente do consentimento necessário para qualificar a para a exaustão do direito de propriedade intelectual, esse, existe quando o titular consente em colocar o produto em circulação".

Nos ordenamentos nacionais, especialmente no brasileiro, após a célebre decisão de 1959 do Supremo Tribunal Federal (Recurso Extraordinário $\left.\mathrm{n}^{\mathrm{a}} 36.415-\mathrm{SP}^{19}\right)$, favorável às importações paralelas $\mathrm{e}$ a exaustão dos direitos de propriedade intelectual, o entendimento jurisprudencial tem caminhado em direção contrária ao posicionamento norte-americano e àquele adotado pela decisão anteriormente mencionada, no sentido de não permitir o princípio de exaustão dos direitos de propriedade intelectual nas relações entre empresas partícipes de um mesmo grupo ou licenciadas ${ }^{20}$.

Nos outros países do Mercosul, com exceção do Uruguai, a jurisprudência tem, reiteradamente, considerado lícitas as importaçóes paralelas, independente da natureza das relações interempresariais apresentadas, desde que o produto, objeto da importação, tenha caráter genuíno ${ }^{21}$.

\footnotetext{
13 Nesta caso, caberia discutír a responsabilidade do titulat do direito de propriedade intelectual pela ruptura de suas obrigaçoes contratuais, frente a seus distribuidores exclusivos locais. A princípio, ao celebrar un contrato de distribução exclusiva, o titular, concedente dessa proteção territorial, obrigase a excluir a si próprio do mercado Vid sobre o tema: AMARAL, Luiz Henrique, "A exaustáo de Direitos e a Importação Paralela na Nova Lei de propriedade Industrial: A evoluça jutisprudencial", Anais do XIX Seminário de Propriedade Intelectual, 1999, pag.120.

iv Vid em Revista Trinestral de Jurisprudència, vol. 10, julho-setembro, 1959, pp.310-312.

21 Entre muitas decisōes, uma recente exemplifica a apelaçäo Civil a $\mathrm{a}^{\underline{3}}$ 227.836-1 - SP, Tectory Indústria de Brinquedos Ltda e outra versus Gamaw Importaçä́o, Comércio e Assessonta Ltda. Solbre a evoluçẫo dos entendimentos judiciais no Brasil sobre o tema da exaustão dos diretto de propriedade intelectual, vid. AMARAL Luiz Henrique, "A Exaustão e a Importação Paralela na Nowa Lei de Propriedade Industrial: A croluçảo judicial", Anais do XIX Semináno Nacional de Propredade Intelectual, Revista da Associação Brasileira da Propriedade Intelectual, 1999, pp.118-126.

21 Como exemplificam os casos: Loreal, Toyota, Philips in FEKETE, Elizabeth K., op.cit, pp.82-84.
} 
No capítulo sobre Direitos de Propriedade Intelectual, da atual minuta de acordo para o estabelecimento da Area de Livre Comércio das Américas - $\mathrm{ALCA}^{22}$, aparece, entre os diversos temas inseridos nas pautas de negociação, a exaustão dos direitos e, como ele, as importações paralelas. Na mencionada proposta, entende-se como consentimento tácito, aquele realizado entre empresas "economicamente vinculadas", ou seja: " quando uma possa exercer direta ou indiretamente sobre a outra uma influência decisiva com respeito à exploração dos direitos sobre a marca, ou quando um terceiro possa exercer a influência sobre ambas as pessoas"

Adota-se, assim, a tendência norte-americana de qualificação do consentimento tácito nas importações realizadas entre empresas de um mesmo grupo societário.

\subsection{Importaçöes Paralelas entre licenciados}

Desde a perspectiva da exaustão internacional do direito de propriedade intelectual ${ }^{23}$, a jurisprudência norte-americana e a européia ${ }^{24}$ têm afirmado a possibilidade do titular do direito de propriedade intelectual proibir importações realizadas por intermediação de fabricantes licenciados do titular da marca no país estrangeiro ${ }^{25}$.

Em recente Acórdão do Tribunal de Justiça da Comunidade Européia de 1/07/99 - Proc. $n^{\underline{a}}$ C-173-98 - Sebago Inc. Ancienne Maison Dubois et Fils As \& GB-Unic SA, a respeito de importações paralelas de sapatos "Dockside", o Emérito Tribunal entendeu que o simples fato de ter, o importador paralelo comprado a mercadoria do fabricante licenciado do titular da marca e exportado para a Comunidade, não indica que o titular comunitário do direito de propriedade intelectual tenha presumido o consentimento para comercialização do bem nesse território ${ }^{26}$.

\footnotetext{
2. Vid texto en www.siceons.org/FTAADraft.

${ }^{23}$ Explicado no item seguinte.

24 Tumbém, a brasileira vem trabalhando a materia de importaçoes paralelas e contratos de licença. Una recente caso sobre a matéria foi o lińgio entre a Reebok Internacional Ltd versus a RBK do Brasil Comério, Importaçăo e Fxportação S/A (Vid. DORJ - III/Sec. I, 15.04.99) a segunda, distribuidora exclusiva dos produtos da Reebok no Brasil, que vinha sofrendo com a concoriência no mercado brasileiro de constantes importaçỏes paralelas de produtos legítimos, adquiridos atraves de outros distribuidores exclusivos existentes da Recbok fora do Brasil. Vid. Comentários em AMARAL. Luiz Henrique, op.cit, pag.120.

25. Vid a decisão K.Mart Corp. v. Cartier, 486 US 281 (1987), onde a Corte de Justiça nonte-americana rejeitou o entendimento do Departamento de Tesouro que permitia importaçăo de mercadorias ali conercializadas, através do licenciaco do titular do direito de propriedade intelectual, exaurindo, assinu, o direito deste, em plettear a impossibilidade da importaçäo em base ao seu não consentimento. 2" A temática da probiç̧a das importaçóes paralelas e as relaçôes de licença, em especial, a existência de cláusulas de "não consentimento" de concorrência, nos contratos de distribuiçăo exclusiva, levantam o conflito entre: a cxistencia de determinaçäo contratual não consentindo a livre comercializaçăo do bem, ou seja, sua livre concorrência, objeto do contrato de distribuição exclusiva, e as normas sobre concorrência ex un determinado mercado. Vid MORAIS, Roberta I. "Exausta dos Direitos de Propriedade Industrial: uma foma de gaxantir a live concorrência", in Estudos sobre Integraçâo, Angela Teresa Gobbi Estrella (et ali), org. Werter Faria, Porto Alegra: Livraria dos Advogados, 2000, pp.193-208.
} 
No tema distribuição ou fabricação exclusiva e importações paralelas caímos num emaranhado de conflitos vinculado às relações entre licenciado e titular dos direitos de propriedade intelectual. Tais conflitos esbarram, quase sempre, em questionamentos relativos à extensão e aos limites das cláusulas de exclusividade territorial ${ }^{27}$ existente nos contratos de licença, assim como, no dever de lealdade decorrente dos contratos de cooperação empresarial, e, finalmente, na necessária perseguição dos titular do direito de propriedade intelectual em coibir as importações paralelas em território cuja zona já foi concedida sob forma exclusiva a um licenciado ${ }^{28}$.

Nesse sentido, cabem, como itens de negociação em contratos de licenças, na prevenção de importações paralelas, as seguintes questões:

i) a delimitação contratual da territorialidade e conseqüente impossibilidade de venda ao estrangeiro nos contratos de licença exclusiva ${ }^{29}$;

ii) venda de produtos objeto destes contratos a terceiros não licenciados e sua importação e comercialização no mercado estrangeiro;

iii) responsabilidade entre o titular da marca e o licenciado exclusivo, quando o primeiro não toma as devidas atitudes necessárias para impedir a "exportação" paralela de seus produtos $s^{30}$.

\footnotetext{
27. A exclusividade territorial, quase sempre existente nos contratos de licença, e de natureza bilateral, "o distribuidor se obriga a não efetuar vendas fora da zona determinada e o fabricante, por sua vez, se compromete a aio designar outro distribuidor no mesmo territorio" (MARZORATL, Osvaldo J. Sistemas de Distribución Comercial. Agencia. Distribución. Concesion. Franquia Comercial, 12.ed. Buenos Aires: Astrea, 1992, pp.65-66).

2 Tä confitos nảo sấo de facil soluço afnal, como probibir a revenda por terceiros compradores, para o mercado do titular da propriedade intelectual? Esta limitaça fere a concorrência do mercado? A venda de uma importante quantia supõe o conhectuento e, conseqücnte, o consentimento para sua revenda o venda? Cono haz un importador para saber se o produto comprado pode ou năo ser revendido no seu território de atuaçăo? Quais são as relaçôes entre licenciados e terceiros compradores? Nesse aspecto, em utma decisão do Tribunal Superior Britànico, - comentada por Gabriel Leonardos, in Anais do XIX Seminário Internacional de Propriedade Intelectual, Revista da Associação Brasileira de Propriedade Intelectual, 1999, pag. 124 - ficou demonstrado, que ao näo estarem limitados contratualmente, os direitos de terceiros adquirentes e revendedores, esses podem ser mais amplos, do que os direitos dos próprios distribuidores exclusivos, incapacitados a exportar produtos legítimos fora de sua zona de exclusividade 2 Podem os licenciados (principalmente de fabricaçäo) vender o produto para importadores paralelos do mercado do titular do direito de propriedade industrial? A princípio, abe ao próprio contrato determinar o espaço territorial de sua atuação.

3) No Brasil, onde as jurisprudências são contraditónas sobre a materia de importaçóes paralelas, no que concerne as relaçoes entre titular de um direto de propriedade intelectual e seus distribuidores exclusivos, vem sendo desenvolvida uma interpretaçăo, no sentido de afirmar que a não realização de medicas de repressão ás importaçoes paralelas, pelo titular da marca ou de outro direito de proprieda. de, em favor de seus distribuidores exclusivos locais, enseja a responsabilidade dos titulares desse direito, visto que, os mesmos possuem o dever de resguardar a exclusividade que haviam concedico ao seu licenciado. Respondem, tais titulares, inclusive, pelas perdas e danos do licenciado exclusivo, acasionados pelas importaçöes paralelas Vid. caso, Reebok International Lid outros \& RBK do Brasil Comécio Importaça e Exportação Ltda, op.cit).
} 
Estes questionamentos revelam a dificuldade de delimitação de unicidade na solução jurídica da licitude das importações paralelas no Brasil e no mundo, sobretudo em função da complexidade e diversidade das formas e relações entre as partes envolvidas no fenômeno jurídico das importações paralelas.

Cabe afirmar, que, exclusivamente no Brasil, o tema do consentimento nas importações paralelas, sofre interpretações muitas vezes contraditórias, justificadas, inclusive, não só pela diversidade dos fenômenos jurídicos que envolvem essas importações, mas, também, por ser esse, ainda, um tema recente e incipiente naquele ordenamento e, consequentemente, o seu desenvolvimento jurisprudencial está longe de possuir uma tendência uniforme.

Tal matéria vem discriminada no borrador do capítulo do acordo ALCA, sobre direitos de propriedade intelectual, legitimando as importações paralelas, desde que o produto original tenha sido colocado no mercado em qualquer país parte da ALCA, diretamente através do titular do direito de propriedade, ou "licenciado ou qualquer terceiro autorizado para isto ${ }^{31}$."

\section{Análise objetiva do consentimento: consentimento em fun- ção da natureza do produto}

Em outra perspectiva, também é questão do debate da extensão da qualificação do consentimento tácito, peça angular na licitude das importaçōes paralelas, a natureza do produto, objeto da importação.

A exaustão é argüida quando o titular do dircito de propriedade já houver diretamente introduzido ou autorizado a comercialização no mercado, de produto similar ou idêntico, ao do objeto da importação paralela.

Sobre o tema, um interessante questionamento foi o realizado no já mencionado caso Sebago ${ }^{32}$, relativo à aplicabilidade da teoria da exaustão internacional, que dentre as questões prejudiciais argüidas ao Tribunal de Justiça das Comunidades Européias, estava a de saber se é qualificado como presumido, o consentimento, quando o titular da marca já tiver permitido a comercialização no mercado do Espaço Econômico Europeu EEE, de produtos idênticos ou similares àqueles para os quais o esgotamento é invocado. Ou se, ao contrário, o consentimento deve referir-se apenas, a cada exemplar do produto para o qual se invoca a exaustão.

\footnotetext{
Apcit.

3. Acorda do TJCE de 1/07/99- Proc n $n^{2}$ C-173-98 - Sebago Ine. Ancienne Maison Dubois et Fils As \& GB-Unic As.
} 
Nessa oportunidade, consagrou o referido Tribunal que o princípio do esgotamento só respeita determinados produtos que tenham sido objeto de uma primeira comercialização, com o consentimento do titular da marca. Assim sendo, o consentimento deve versar, sempre, sobre cada exemplar do produto, para o qual o esgotamento é invocado. Não sendo assim acatado, a alegação da GB-Unic - sociedade belga importadora paralela - que a comercialização no EEE, mediante o consentimento do titular da marca, de um lote de mercadorias, esgotava o direitos conferidos pela marca relacionados à comercialização de outros lotes desse produto ou de produtos similares ao mesmo.

Outro elemento da uma análise objetiva do princípio de exaustão é a impossibilidade de que o produto objeto da importações paralelas sofra qualquer classe de alteração, incluindo a seu envase e embalagem ${ }^{33}$. Tais alterações excepcionam a aplicação do princípio de exaustão. Essa exceção está prevista no borrador do acordo da ALCA quando o mesmo possibilita a exaustão sob a condição de que "os produtos, os envases e embalagens que estiverem em contato imediato com tais produtos não tenham sofrido nenhuma modificação ou alteração".

Além das questões relativas à problemática do consentimento, a exaustão do direito de propriedade intelectual, também e, sobretudo, dependerá das limitações geográficas/ territoriais impostas pelas legislações nacionais e/ou regionais para a exploração exclusiva de determinados direitos pelo seu titular. Esta será a temática a seguir discutida.

\section{Limites geográficos e a aplicação do princípio de exaustão de direitos}

Como afirmado anteriormente, entende-se por exaustão um princípio do direito de propriedade intelectual, que implica em que o direito de exclusividade não confere ao seu titular ${ }^{34}$ o poder de controlar a revenda do produto protegido, uma vez que este produto tenha sido colocado no mercado, por ele ou por seus licenciados ${ }^{35}$. A fundamentação para a explicação

\footnotetext{
3) A existência de alteração nas condiçôes do produto, inclusive envase e embalagem, legitimam, a não adoça do princípio de exaustấ. Esta questão vem sendo discutida, quando da aplicaça da regulamentnça européia sobre marcas, especificamente, pelo att. $7^{\text {a }}$, da Diretiva 89/104/EEC, 1989, JOCE. (L 40). Vid comentários URLESBERGER, Franz C. "Legitimate reasons for the proprietor of a trade mark registered in the EU to oppose further dealings in the goods after they have been put on the market for the first time", Common Market Law Review, vol 36, n* 6, 1999.pp. 1195-1228.

3 Exceto certas circunstâncias, como aquelas de suas exceçoes.

35. ALEXANDER, Willy, "Exhaustion of Trade Mark Rights in the Europear Economic Area", European Law Review, vol. 24, 1, 1999, pag. 56.
} 
de tal princípio reside na afirmação de que o direito de exclusividade concedido por lei aos titulares está limitado à primeira autorização de venda em um determinado território. Depois desta, o direito está esgotado.

A delimitação geográfica do mencionado princípio refere-se à dimensão territorial em que o mesmo opera, ou seja, se a exaustão refere-se apenas a vendas autorizadas realizadas dentro do mercado naciona ${ }^{36}$, regional ${ }^{37}$; ou se ao contrário, também se aplica no caso de vendas autorizadas realizadas fora do mercado nacional ou regional, ou seja, no mercado internacional.

\subsection{Modelos regionais e os limites internacionais da exaustão}

No modelo europeu de integração, o princípio da exaustão ganha duas dimensões geográficas: a exaustão regional e a internacional. A primeira, desenvolvida em especial pela via da interpretação jurisprudencial, baseada na interpretação dos artigos 30 a 36 do Tratado de Roma (hoje artigos 28-30 de Tratado de Amsterdâ33), apenas admite o limite à livre circulação de mercadorias quando esta estiver justificada em base à derrogação dos propósitos salvaguardados pelo próprio direito de propriedade. Estando este protegido, tendo o titular comercializado por primeira vez o produto, no mercado da comunidade, não se justifica a limitação da circulação do bem a través da proibição de importações paralelas ${ }^{39}$.

A segunda vem sendo desenvolvida jurisprudencialmente, no sentido de se definir se a exaustão preconizada regionalmente estende-se também, nas importações paralelas com agentes extra comunitários.

Em recente decisão, caso Silhouette International Schmied GMB \& Co.Kg contra Hartlauer Ham. $\mathrm{MbH}^{40}$ entendeu o Tribunal de Justiça das Comunidades Européia, pela não permissão aos Estados membros, da possibilidade de preverem, nas suas legislações nacionais, o esgotamento dos direitos de propriedade intelectual em relação a produtos comercializados fora do EEE, pelo titular ou com seu consentimento ${ }^{41}$. Assim, o regime europeu estabelece que o titular de um direito de propriedade intelectual, no caso específico, um registro de marca, pode impedir a importação de produtos de sua marca, que hajam sido colocados à venda pela primeira vez fora daquele espaço europeu ${ }^{42}$.

\footnotetext{
37 Tal como estabelece o artigo 13, do Protocolo de Harmonização de Normas em Matérias de Desenho Industrial no Mercosul, de 12.10 .98 (ainda não en vigor).

3* Artigos constantes do Capítulo II - A proibição das restrições quantitativas entre os Estados-mem bros, do Tratado de Amsterdã. Vid. Tratado de Amesterdão, Coimbra:Almedina, 1998.

3y Centrafarm B.V. v Winthrop B.V., 1974, E.C.R., 1183.

40 Proc. $\mathrm{n}^{\underline{\underline{a}}} \mathrm{C}-355 / 96$, op.cit.

4) O impossibilidade de exaustão internacional dos direitos de propriedade intelectual sofre severas críticas doutrinárias, Vid. ALEXANDER, Willy, op.cit., pag.59.

${ }_{2}$ Parecer no Comitê Econômico e Social sobre o "Esgotamento dos direitos conferidos pela marca registrada", Bruxelas 24, de janeiro de 2001, CES 24/2001 ES - CF/if.
} 
Não é, por conseguinte, recepcionado o princípio de exaustão internacional dos direitos de propriedade intelectual. A justificativa para tal posicionamento reside na necessidade de eliminação das disparidades que as legislações nacionais sobre a temática importariam, ao regulamentarem a exaustão internacional, frente à livre circulação de mercadorias no mercado comum.

Na ALCA, as propostas existentes no capítulo sobre Direitos de Propriedade Intelectual, limitam-se à dimensão à regional, ou seja, os titulares de direitos de propriedade intelectual não poderão impedir a comercialização de produtos que tenham sido colocados no mercado por primeira vez, por eles por alguém por eles autorizado ou por seus licenciados. Não consagrada, assim, a exaustão internacional dos direitos de propriedade intelectual.

\subsection{A regulamentação multilateral sobre a exaustão internacio- nal: linhas de um debate subjetivo}

A regulamentação das importações paralelas envolve uma balança de interesses antagônicos entre produtores (empresa) e consumidores. Os primeiros, buscando a maximização de seus investimentos a partir da exploração plena de seus direitos de propriedade intelectual; e os consumidores, solicitando maiores canais de acesso aos produtos em melhores condições de oferta ${ }^{43}$.

Com a multilateralização das atividades empresariais, fomentada, fortemente, pelo processo de globalização da economia, este dilema ganha novos contornos e dimensões.

No âmbito do direito internacional econômico, em especial, no âmbito da regulamentação multilateral da Propriedade Intelectual, o Acordo sobre os Aspectos dos Direitos de Propriedade Intelectual relacionados com o Comércio - TRIPs ${ }^{44}$, anexo ao acordo que deu origem a Organização Mundial do Comércio-OMC, é omisso em relação à possibilidade de exaustão de direitos.

\footnotetext{
4. Vid. ABBOTT, Frederick, op.cit, pag, 612 .

4. $\mathrm{O}$ axtigo $27^{2} \mathrm{da}$ TRUPs - que muita discussão trouxe, especialmente, nas acusaçőes realizadas contra o art. 68 da Lei de Propriedade Intelectual brasileira, a respeito de licenças compulsórias - apenas define a impossibilidade de discriminação quanto ao fato de que os bens, objeto da patente, sejam produzim dos ou importados localmente. Vid. SCHOLZE, Simone, "Fabricaçăo local, licença compulsória e importaça paralela na Lei de propriedade Industrial", Revista da Associação Brasileira de Propriedade Intelectual, $n^{2} 54$, setembro - outubro, 2001, pag. 11. Vid sobre o caso brasileiro, ROSENBERG, Tina, "Look at Brizil", The New York Times, 28/01/2001.
} 
De fato, menciona o acordo sob a epígrafe "Esgotamento", no seu artigo sexto que "para efeitos da resolução de conflitos ao abrigo do presente Acordo e sem prejuízo do disposto nos artigos $3^{\mathrm{a}}$ e $4^{\mathrm{a}}$ nenhuma disposição do presente Acordo será utilizada para tratar a questão do esgotamento dos direitos de propriedade intelectual ${ }^{45}$ "

Desta forma, pode-se concluir que, na ausência de imposição específica, podem os Estados partes gozarem de eventual liberdade na regulamentação do princípio de exaustão internacional dos direitos de propriedade intelectu$a^{46}$. Mas a realidade das relaçôes internacionais demonstra a enorme dificuldade que encontram determinados Estados, em especial, em desenvolvimento, para o estabelecimento unilateral da exaustão internacional de direitos intelectuais, mesmo que excepcionalmente ${ }^{47}$ e em caráter de emergência.

\section{Conclusão}

Com o limite da ausência de uma regulamentação favorável à exaustão internacional dos direitos de propriedade e a afirmativa da regulamentação multilateral sobre a impossibilidade da aplicação da exaustão internacional na solução de conflitos por ventura existentes, o caminho adotado na bifurcação de interesses intrínsecos à regulamentação dos direitos de propriedade intelectual, em especial, ã temática das importações paralelas pela

\footnotetext{
45 A formula prevista neste artigo, conforme Frederick Abbott, resultou de um compromisso tomado, quando de sua negociação, entre as partes do Acordo Geral sobre Tartas e Comércio - GATT. Desse compromisso, duas afirmaçốs são extraidas: a) a primeira, que o tema impotaçós paralelas nẵo foi inadvertidamente excluido do acordo. Sua exclasäo fó fruto da falta de consenso entre Estados Unidos da América, cuja posiço sempre fó contrária a inclusăo da regulamentaçăo das impontaçóes paralelas, de um lado, e os Países em Desenvolvimento, de outro, cuja posiçâ, majoritária, era favorável a dita regulanentação; b) a segunda, não existindo regulamentação multilateral a respeito, os Estados menbros da Organização Mundial do Comércio, reservam para si, o direito de regularem as importaçós paralelas. Vid. ABBOTT, Frederick, op.cit, pag.609.

to $\mathrm{Na}$ esfera dos direitos nacionais, tradicionalmente, os Estados Unidos, na qualidade de grandes exportadores de diretos de propriedade intelectual, são contrários à limitação da exaustão internacional dos diretos de propriedade intelectual.

47 Como pode ser o sctor farmacêtico, neste 100 companhias controlam $90 \%$ dos produtos voltados ao consumo humano, repartindo o mercados mundial de produtos farmacêuticos, conforme suas variáveis lucrativas. Vid. BRUNNER, Adriana G. "As Patentes Farnacêuticas e a Licença Compulsónia: O fim de uma batalha entre Estados Unidos e Brasil", Revista da Associaģo Brasileifa de Propriedade Intelectual, $\mathrm{n}^{2} 55$, novembro-dezembro, 2001, pag.26. O mencionado setor foi fruto de uma delicada controvérsia entre Brasil e Estados Unidos, da qual resultou, na ultima reuniāo Ministerial da OMC, em DOHA, da Dedaraçio relativa ao acordo TRPSs e Saúde Pública (WT/MIN(01)/DEC/2), adotada en 14 de novembro de 2001. Esta permite aos Estados membros da OMC a adoça de medidas para proteçio da sab́de publica, em particular, promovendo o acesso a medicamento em seus mercados, através da flexibilizaço dos direitos de propredade intelectual, cono a concessão de licencas compulsónias para a cxploraçio de produtos farmacèticos.
} 
principal organização internacional vinculada a regulamentação do comércio, a OMC, foi tendenciosa aos interesses da legitimação empresa, reduzindo, substancialmente, as facilidades de acesso ao mercado aos empresários importadores de direitos de propriedade intelectual e, especialmente, aos consumidores.

Estes últimos continuam arcando com o preço que supõe o isolamentos de determinados mercados, em função dos interesses econômicos de alguns setores industriais, acobertados pela proteção, sem limites, de um direito de exclusividade ${ }^{48}$. Difícil é o trabalho de harmonizar tais fatos à essência dos direitos de propriedade intelectual, ou seja, a promoção à invenção e a criatividade.

Em determinados setores fundamentais para o desenvolvimento humano, como pode ser o da saúde, exceções à proibição de importações paralelas, poderiam representar a diminuição do isolamento dos mercados aos interesses apenas economicistas, e, assim, a possibilidade de enfrentamento a diferentes pandemias que devastam sonhos por todo o planeta $^{49}$.

Os caminhos do labirinto da construção da Área de Livre Comércio das Américas- ALCA são rigorosos e antagônicos e suas bifurcações precisas. Os portóes deste projeto passam pelo aprofundamento do estudo das diferenças e exceções existentes nas relações econômicas regionais e a conseqüente necessidade de flexibilização de dogmas preestabelecidos, como a não aceitação da exaustão internacional dos direitos de propriedade intelectual.

\section{BIBLIOGRAFIA}

ABBOTT, Frederick., "Firts report (Final) to the committee on international trade law of the international law association on the subject of Parallel Importation", Journal of International Economic Law, 1998.

ADIERS, Cláudia M., "Importações Paralelas e seus reflexos no Direito contratual e concorrencial", Revista da Associação Brasileira da Propriedade Intelectual, $\mathrm{n}^{\mathrm{a}}$ 64, 2003.

ALEXANDER, Willy "Exhaustion of Trade Mark Rights in the European Economic Area", European Law Review, vol. 24, 1, 1999.

AMARAL, Luiz Henrique, "A Exaustão e a Importação Paralela na Nova Lei

* Criticas sobre a ausência da exaustäo internacional dos direitos de propriedade intelectual são ouvidas en diferentes vozes, como a do próprio Comitê de Direito Mercantil Internacional da "International Law Associtaion - ILA", Vid. ABBOTT, Frederick, op.cit.

19 Na Árrica, um de cada cinco adultos estão infectados com o víns do HIV, no Brasil, possúrnos mais de 150.000 casos, onde 6.000 , são de menores de 13 anos - dados do Ministério da Saúde brastleiro. 
de Propriedade Industrial: A evolução judicial”, Anais do XIX Seminário Nacional de Propriedade Intelectual, Revista da Associação Brasileira da Propriedade Intelectual, 1999.

ASCARELLI, Túlio, Enciclopédia Jurídica Soibelman, Rio de Janeiro:Saraiva, 1998. BEIER, Friedrich-Karl, "Propriedad Industrial y libre circulación de mercancías en el mercado interior y en el comercio con terceros Estados", Revista General de Derecho, nª 549, Junho, Valencia, 1990.

BULGARELLI, Waldírio, Concentração de empresas e Direito Anti-Trust, São Paulo:Atlas, 1996.

COMPARATO, Fábio $\mathrm{K}, \mathrm{O}$ Poder de Controle na Sociedade Anônima,3.ed.,São Paulo:RT,1983.

BRUNNER, Adriana G., "As Patentes Farmacêuticas e a Licença Compulsória: O frm de uma batalha entre Estados Unidos e Brasil", Revista da Associação Brasileira de Propriedade Intelectual, $\mathrm{n}^{ \pm}$55, novembro-dezembro, 2001. DEL NERO, Patrícia Aurélia, Propriedade Intelectual: a tutela jurídica da biotecnologia. São Paulo: Revista dos Tribunais, 1998.

DINIZ, Maria Helena, Dicionário Jurídico, São Paulo: Saraiva, 1998.

FEKETE, Elizabeth K., "Importaçôes Paralelas: A implementação do princípio de exaustão de direitos no Mercosul, diante do contexto de globalização", Anais do XXVI Seminário Nacional de Propriedade Intelectual,1997.

HARLANDER, Lisa, "Exhaustion of trademark rights beyond the European Union in light of Silhouette International Schmied V. Hartlauet Handelsgesellschaft. Toward stronger protection of trademark right eliminating the gray market", Georgia Journal of International and Comparative Law, vol 28, $\mathrm{n}^{32} 2,2000$.

MARZORATI, Osvaldo J., Sistemas de Distribución Comercial. Agencia. Distribución. Concesión. Franquia Comercial, 12.ed., Buenos Aires: Astrea, 1992. MORAIS, Roberta J., "Exaustão dos Direitos de Propriedade Industrial: uma forma de garantir a livre concorrência", in Estudos sobre Integração, Angela Teresa Gobbi Estrella (et alli), org. Werter Faria, Porto Alegra: Livraria dos Advogados, 2000.

ROSENBERG, Tina, "Look at Brazil", The New York Times, 28/01/2001.

SCHOLZE, Simone, "Fabricação local, licença compulsótia e importação paralela na Lei de propriedade Industrial", Revista da Associação brasileira de propriedade Intelectual, $\mathrm{n}^{\mathrm{a}}$ 54, setembro - outubro, 2001.

URLESBERGER, Franz C., "Legitimate reasons for the proprietor of a trade mark registered in the EU to oppose further dealings in the goods after they have been put on the market for the first time", Common Market Law Review, vol 36, $\mathrm{n}^{3}$ 6, 1999. 